\title{
Pressure fluctuation analysis for charging pump of chemical and volume control system of nuclear power plant
}

\author{
Qiang Chen, Yin-hui Che and Jian-jun Guan \\ SuZhou Nuclear Power Research Institute Co. Ltd., Shenzhen, Guang dong, 518038, China
}

\begin{abstract}
Equipment Failure Root Cause Analysis (ERCA) methodology is employed in this paper to investigate the root cause for charging pump's pressure fluctuation of chemical and volume control system (RCV) in pressurized water reactor (PWR) nuclear power plant. RCA project task group has been set up at the beginning of the analysis process. The possible failure modes are listed according to the characteristics of charging pump's actual pressure fluctuation and maintenance experience during the analysis process. And the failure modes are analysed in proper sequence by the evidence-collecting. It suggests that the gradually untightened and loosed shaft nut in service should be the root cause. And corresponding corrective actions are put forward in details.
\end{abstract}

\section{Introduction}

Chemical and Volume Control System (RCV) is one of the most important systems of primary circuit in pressurized water reactor (PWR) nuclear power plant to provide the reactor coolant system (RCP) with following services as it is designed. On one hand, RCV is able to maintain the pressurizer a programmed water level by utilizing its charging and let-down function. On the other hand, RCV in combination with the make-up system (REA) can tune the boron concentration so as to reduce the reactivity variations induced by temperature change, fuel burning and xenon transients. Through measurement of removing corrosion and demineralization of fission products in ionic and particles, the reactor coolant activity level can be effectively controlled. There are three charging pumps in RCV system capable of supplying charging flow with sufficient pressure. To be specifically, the RCV002PO and RCV003PO can be switched in routine service, while the RCV001PO is functioned as a standby pump when RCV002PO and RCV003PO are being switched. In addition, the charging pumps in RCV system is considered as high head safety injection pumps in case small breaks occur in the primary circuit pipeline. Therefore, the charging pump is much accounted of nuclear power station, RCC-M safety Class 2 as one of the most important devices.

Recently, the RCV002PO has been restarted about ten times in a power nuclear power plant from June to September in 2014, with charging pressure decreasing 0.5 bar between neighbouring setups. The charging pressure has dropped from the initial 177 bar to the final 173 bar until September. However, the charging pressure remained stable while the pump was operating continuously (as shown in Fig. 1(a)). In October, the
RCV system pushed up the flow, resulting in the charging pressure decreasing from 173 bar to 168.5 bar and apparent low pressure alarm triggered (alarm value is 169 bar). In spite of consecutively dramatic decrease, the charging pressure recovered to $175 \mathrm{bar}$ after a periodic test RPB010 (Reactor protection 010 Test, B column) being carried out on 24th October. However, on 27th October it redropped to 168.5 bar again when performing another periodic test RPA011 (Reactor protection 011 Test, A column).

Under the circumstance that charging pump pressure drops ceaselessly, this phenomenon may make RCV system be isolated when water level becomes out controlled by the primary circuit. Degrading function of charging pump, thereby affects high pressure safety injection function. Hence from we are motivated to unveil this phenomena by virtue of a systematically investigation.

Root Cause Analysis (RCA) is a method that is used to address a problem or non-conformance, in order to get to the "root cause" of the problem. It is used so we can correct or eliminate the root cause, and prevent the problem from recurring. RCA method arose in the 1950s as a formal study by the National Aeronautics and Space Administration (NASA) in America. But it didn't become a technical until that was used in three island nuclear accident. There are several commercial RCA methods available in the world now. Listed are examples of some popular methods, TapRooT ${ }^{\circledR}$ system, Apollo Root Cause Analysis (ARCA), REASON® and PROACT ${ }^{\circledR}$. These methods have different characteristics and analysis steps. They are used in a wide variety of industries, such as resources, petro-chemical, manufacturing, aerospace, telecommunications and healthcare, to guide problem analysis. In a nuclear power station, Equipment Failure 
Root Cause Analysis method (ERCA) was usually used. It utilizes a 6-step sequential process to find the root cause of an event: a) Define the problem of an event, b) Collecting equipment data information, c) Listed the equipment failure modes and analysis their possibility, d) Identify the root cause, e) Formulate the corresponding corrective actions, f) Tracking and assessment the effects of the corrective actions, as shown in figure 2 .

This study introduces the ERCA's process of this event to find out the root cause for pressure fluctuation and come up with corresponding corrective actions.

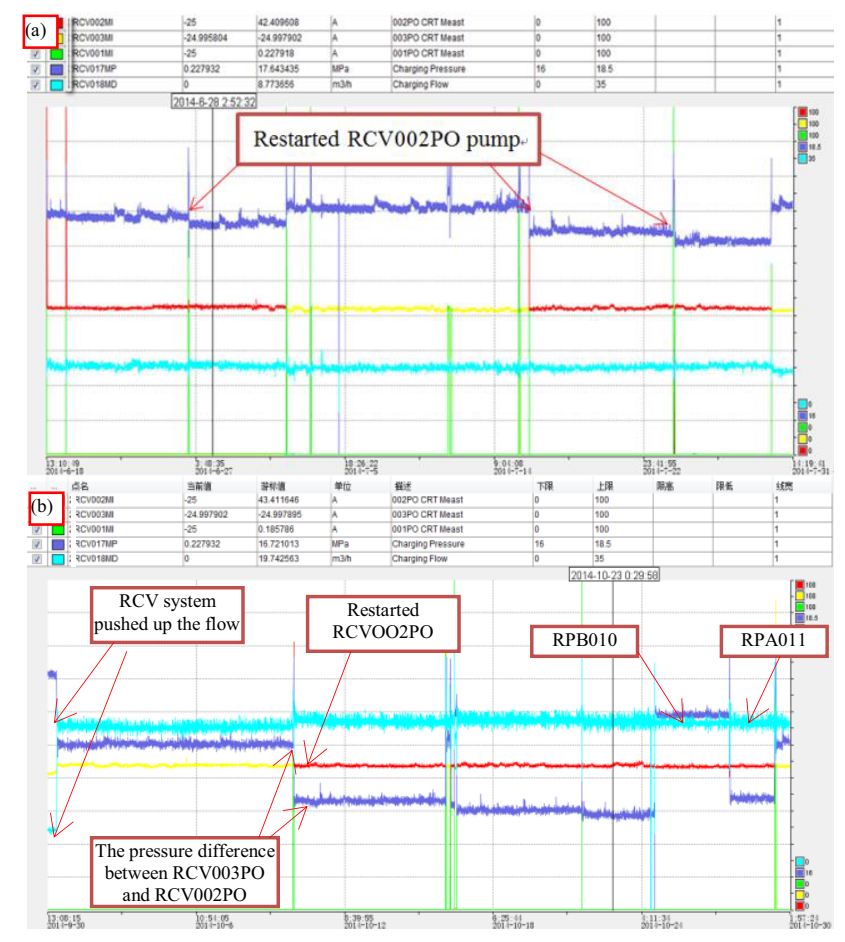

Figure 1. (a) The charging pressure decreased after the pump being restarted (b) RCV002PO apparent low pressure alarm triggered.

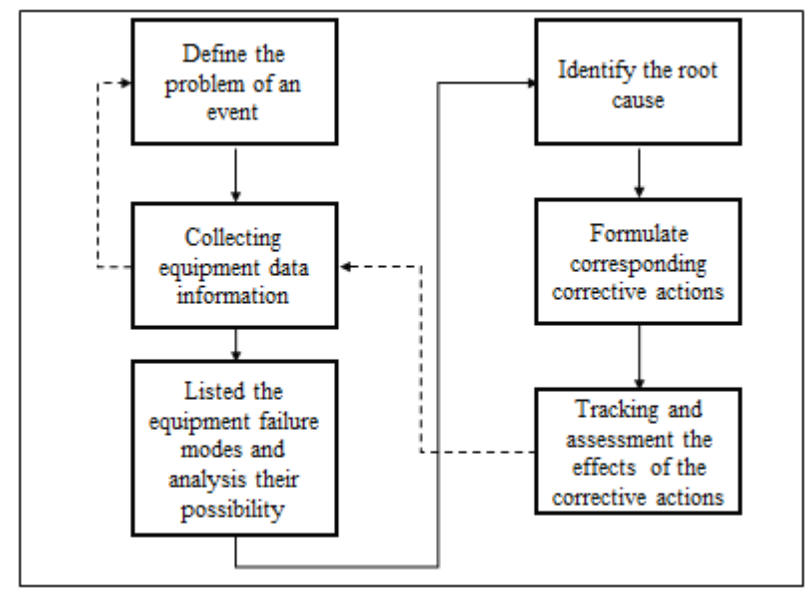

Figure 2. The 6-step of Equipment Failure Root Cause Analysis method (ERCA).

\section{Root cause analysis}

\subsection{Process analysis}

The investigation and analysis are performed in accordance with following steps:

1) Setting up RCA project task group, to collect the event background and equipment information, and experience feedback from similar equipment.

2) Surveying on the charging pump running records, to confirm the problem and the scope of the fault, such as real-time monitoring records, regular test records and charging pump's weekly running state records, etc.

3) Surveying and collecting equipment data information by methods of personnel-interviewing and so on, including equipment design, maintenance manuals, drawings, maintenance of the original data and relevant papers, to analyse relevant data and evidence.

4) Enumerating the possible failure modes according to the charging pump's actual pressure fluctuation in the nuclear power plant, to formulate action plans.

5) Analysing, demonstrating and concluding all failure modes step by step after evidence-collecting. The subsequent forensic analysis on characteristics of each failure model can collect additional evidences.

6) Probing into the most possible causes and related influencing factors of the pump pressure fluctuation through comprehensive analysis concerning the survey and data of the failure modes.

7) Constructing the logical process of the event to explain the mechanism of the pump pressure fluctuation. Address the root cause and formulate corresponding corrective actions.

8) Tracking and assessment the effects of the corrective actions and feedback the experience.

\subsection{Overview of the charging pump equipment}

The charging pump group is composed of $6.6 \mathrm{kV}$ driving motor, speed increasing gear box, pump and other components. The schematic illustration of pump group is shown in Fig. 3. The motor is manufactured by Jiamusi Electric Machine CO., ltd. (China). The charging pump is horizontal multistage centrifugal pump produced by KSB AG (Germany).

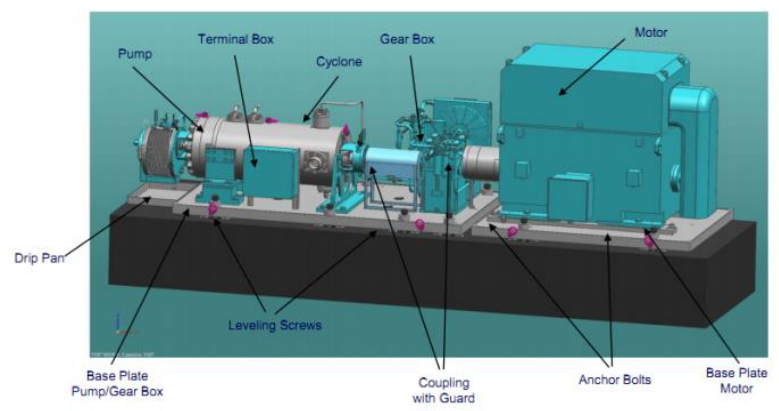

Figure 3. Charging pump group.

The pump is mainly made from impeller, guide vane, pump shaft, mechanical seal, bearing, balance drum, pump casing and pump cover. There are a radial bearing in driving end of the pump and a thrust bearing in nondriving end, as shown in Fig. 4. The pump is designed 
with full core pulling which is very convenient during the overhaul.

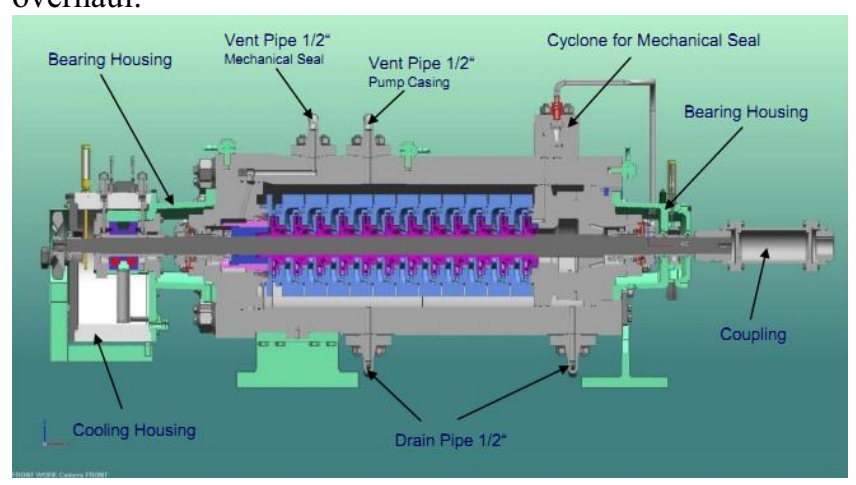

Figure 4. Charging pump body structure.

- Pump Type/Model: horizontal ring-section with 12 stages RHM 100-205.12

- Pump Capacity Maximum: 160m3/h

- Pump Capacity Minimum: 13.6m3/h

- Head /Speed: max. 1810m/ 4,657r/min

- Pump Bearing: single roller bearing (DE) double tapered roller bearing (NDE)

- Lubrication type: oil bath (DE)/oil injection (NDE)

- Motor Capacity: 630kW

- Safety Class: Class 2, acc. to RCC-M Edition 2000, Addendum June 2002

\subsection{Failure mode analysis}

Analysing and troubleshooting the charging pressure decrease is of extreme importance to have the reasons for charging pump's pressure fluctuation be uncovered quickly and accurately. And the possible failure modes are listed ad below:

1) Valves leakage

2) Small flow anomaly

3) Foreign materials in pipeline or pump body

4) Pipeline gas accumulation or gas entrance

5) Wear of internal pump parts

6) Centre offsetting between impeller and diffuser

\subsubsection{Valves leakage}

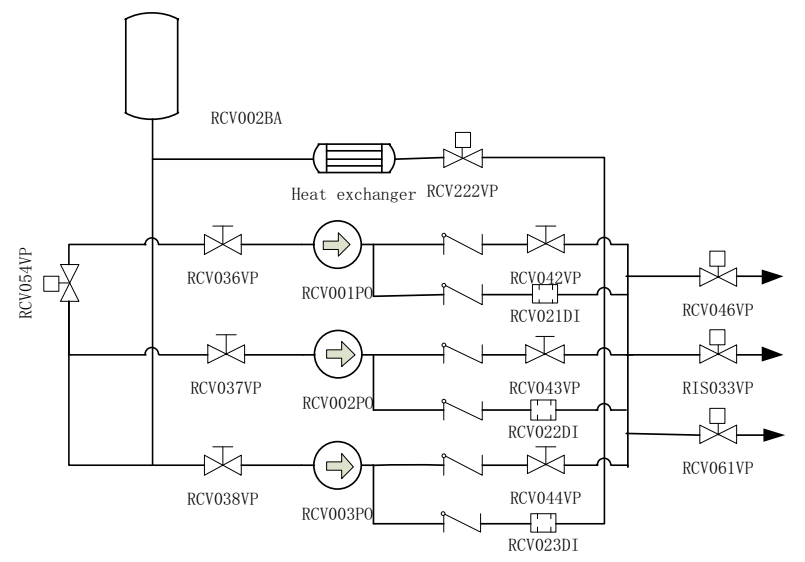

Figure 5. Local flow chart of RCV system.

In order to facilitate the inter-switching among three charging pumps, the inlet and outlet pipeline isolation valves are not allowed to close as usual. The check valves could prevent backflow from the pump outlet and small flow line (as showed in Fig. 5). If the check valve leaked, the pump outlet flow will be diverted, thereby giving rise to the charging pressure decrease.

However, there is no abnormal phenomenon occurring in the case of disintegration of the outlet check valves during the overhaul. The result shows that the possibility of valves leakage is low.

\subsubsection{Small flow anomaly}

If the flow rate of small discharge pipe of the pump outlet increased, the charging pressure will decrease. Once that scenario was found in an incident, investigators may measure the flow data using ultrasonic flow meter, as it can be seen in table 1 .

Table 1. Pressure and flow data of the pumps.

\begin{tabular}{|c|c|c|c|c|}
\hline & $\begin{array}{c}\text { Inlet } \\
\text { pressure } \\
\text { (bar) }\end{array}$ & $\begin{array}{c}\text { Charging } \\
\text { pressure } \\
\text { (bar) }\end{array}$ & $\begin{array}{c}\text { Outlet } \\
\text { flow } \\
\left(\mathrm{m}^{3} / \mathrm{h}\right)\end{array}$ & $\begin{array}{c}\text { Small } \\
\text { flow } \\
\text { pipeline } \\
\text { flow } \\
\left(\mathrm{m}^{3} / \mathrm{h}\right)\end{array}$ \\
\hline $\begin{array}{c}\text { RCV002PO } \\
\text { single pump } \\
\text { operation(2) }\end{array}$ & 1.66 & 168.5 & 39.11 & 14.77 \\
\hline $\begin{array}{c}\text { RCV001PO } \\
\text { single pump } \\
\text { operation }\end{array}$ & 1.68 & 175.3 & 38.40 & 12.89 \\
\hline $\begin{array}{c}\text { RCV003PO } \\
\text { single pump } \\
\text { operation }\end{array}$ & 1.80 & 172 & 38.60 & 13.90 \\
\hline
\end{tabular}

As shown in Fig. 6, when the flow rate of charging pump increases $1 \mathrm{~m} 3 / \mathrm{h}$, the outlet pressure will drop by 0.6 bar. In the case of the outlet pressure of the pump arriving at 169 bar, namely the alarmed value, the bypass flow will accordingly increase at least $10 \mathrm{~m}^{3} / \mathrm{h}$. But the flow of small flow line cannot approach to $23.6 \mathrm{~m}^{3} / \mathrm{h}$ (as it illustrated in table 1).

The aforementioned result suggests that the possibility of the flow rate increase of the small pipe is low. 


\subsubsection{Foreign materials in pipeline or pump body}

Foreign materials in pipeline or pump body is of extreme importance that it may result in the pressure of pump. However, the results investigated in our study have shown that the very small possibility for foreign materials blocking the pipeline and pump body.

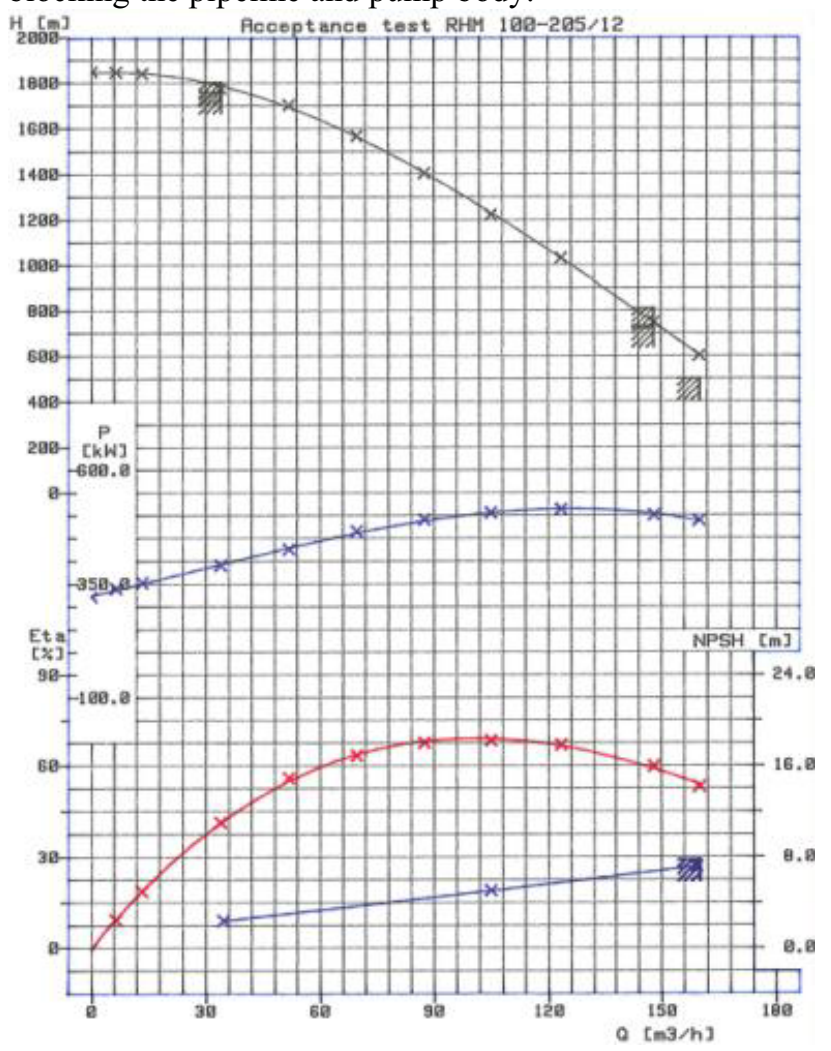

Figure 6. Performance curves of RHM 100-205.12 pump.

\subsubsection{Pipeline gas accumulation or gas entrance}

If the gas in pump body or pipelines accumulated, it will accordingly make the pump pressure be decreased. And continuous intake gas will also affect the pump efficiency, resulting in reduced pump output.

In line with process requirements, the charging pump was filled with water and exhausted gas after the charging pressure low alarm had been reported, but the outlet pressure of the pump was still low. The vent and drain pipelines are showed in Fig. 4. The possibility of gas accumulation can be ruled out.

If the gas entered the pump body continually during operating, the gas-liquid two-phase flow will lead to the pump vibration, and the motor current will be reduced. But the pump group vibration was normal and the motor current maintained a smooth during the event. Therefore, the possibility of continuous intake is low.

\subsubsection{Wear of internal pump parts}

If the rotation parts of pump were substandard or O-rings seal were broken, they will increase the risk of 1 internal flow leakage, resulting in reduced efficiency to the pump.

The inspection results concluded during overhaul are listed as following:
- Inlet clearance of the impellers meets the requirements.

- Outlet clearance of impellers meets the requirements.

- The clearance between the throttle sleeve and the balance drum meet the requirements.

- All kinds of O-ring seals meet requirements.

There were no significant anomalies of the rotation parts of pump during overhaul inspection (as shown in Fig. 7). The impeller and the balance drum wore lightly where the sizes of the balance drum met the standard. Therefore, the possibility of the rotation parts of pump wear or O-rings seal broken can be excluded.

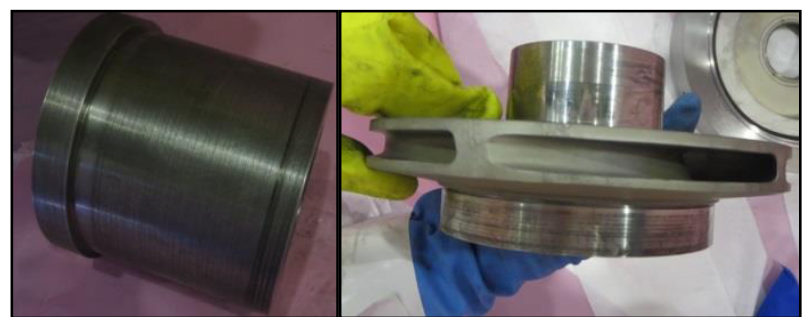

Figure 7. Balance drum and the impeller of pump.

\subsubsection{Centre offsetting between impeller and diffuser}

Due to the existence of various capacity losses, the actual efficiency of the pump is lower than the theoretical value (pump shaft power) in the actual operation of the pump. The pressure head becomes lower while the efficiency of the pump is decreasing. The actual pump efficiency $(\eta)$ depends on the volume efficiency, mechanical efficiency and hydraulic efficiency.

$$
\eta=\eta_{h} \eta_{v} \eta_{m}
$$

$\eta_{v}:$ The volume efficiency of the pump

$\eta_{m}$ : The mechanical efficiency

$\eta_{h}$ : The hydraulic efficiency

The hydraulic efficiency of the charging pump refers to the capacity loss induced by the change of the flow resistance, the area and the direction of the flow, and the circulation and vortex in the impeller passage. When the deviation between the centre of the impeller and the centre of the diffuser reaches its lowest, the hydraulic efficiency of the pump will be the highest [1]. While the hydraulic centre changes, the flow resistance increases, the hydraulic efficiency of the pump will be decreased (as shown in Fig. 8).

The radial cylindrical roller bearing (NU type) in charging pump's driven end (DE) tunes the inner ring movement with the shaft and there is a thrust bearing in pump's non-driven end (NDE) shafting expansion dead point. The shaft nut can be utilized to tight the thrust bearing, but it can be expanded only towards the driven end in the case that shaft is heated via flow.

When the pump operated, the axial forces of the impeller, balance drum and thrust bearing achieved a balance. If the impeller axial force was greater than the balance drum axial force, the temperature of DE roller of thrust bearing will be higher than the NDE roller, viceversa (as shown in Fig. 9). 
However, an inferior situation may occur. To be specifically, if the shaft nut loosed, and the impeller axial force was greater than the balance drum axial force, the actual efficiency of the pump will be decreased simultaneously. Since the multistage impellers moves towards the drive end with the shaft shoulder, it has led to the deviation between centres of impeller and the diffuser. In fact, it was the loosed shaft nut actually found during the overhaul.

In this event, charging pressure decreased when starting up the pump in comparison with the last run in each time. However, the charging pressure remained stable when the pump was operating continuously, because there was an axial impact during axial force balance process once the charging pump had been started. If the tighten force of the shaft nut was not strong enough, it will be loosed slightly after starting the pump in each time [2-5]. But the shaft nut will not get loosed when the pump keeps operating, because the impeller will take the shaft with the nut abutting the thrust bearing.

When the balance drum axial force is greater than the impeller axial force, the balance drum will bring the shaft moving towards to the NDE through snap ring. In this situation, the centres of impeller and the diffuser will not be deviated even if the shaft nut was loosed.

The charging pressure was reverted to 175 bar when a periodic test RPB010 had been carried out on 24 October, in which it was used to open a valve downstream of the pump. After that, the charging pressure re-dropped to 168.5 bar again when performing another periodic test RPA011 on 27 October and the RPB011 test was approaching to a valve in small follow pipeline of the pump. It is worthy to notice that the temperature of the thrust bearing changed when executed RPB010 and RPA011 test (as showed in Fig. 10), meaning that the axial forces of impeller and balance drum changed. This is the RHM 100-205.12 pumps' characteristic. When the inter parts wear or the flow changes, the axial force will change [6].

After completing RPB010 test, the balance drum axial force is larger than the impeller axial force. The channel centre of the suction stage impeller and the diffuser coincides again. The outlet pressure of the pump recovers. But the RPA011 test make the axial force change again, the efficiency of the pump decreases once more.

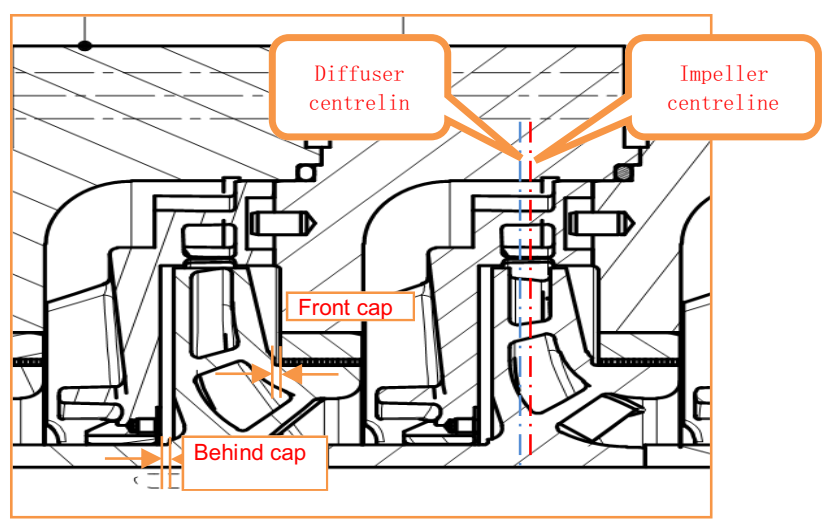

Figure 8. Schematic diagram of impeller centreline and diffuser centreline.

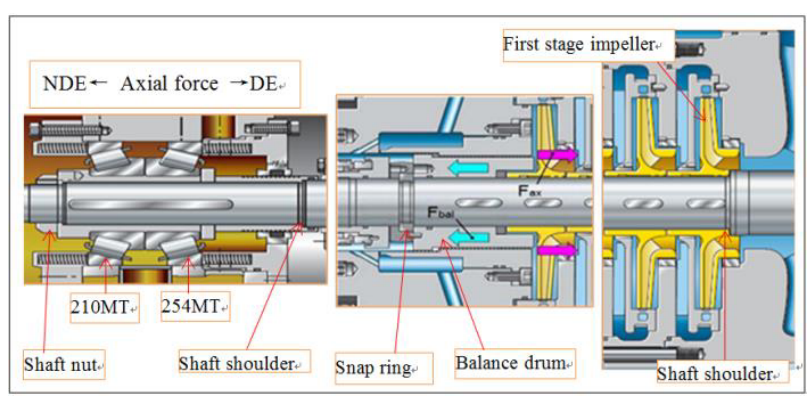

Figure 9. Schematic diagram of charging pump's axial force.

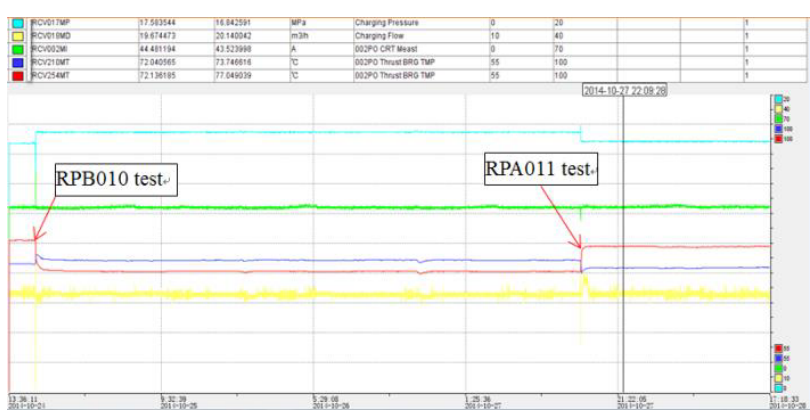

Figure 10. The RPB010 test and RPA011 test.

In summary, the failure mode of centre offsetting between impeller and diffuser of the pump will influence the hydraulic efficiency, and it can be accounted for the entire failure phenomenon. Its possibility is highest than other factors.

\section{The result and corrective action}

\subsection{Cause and effect diagram}

The cause and effect diagram was illustrated as below for better understanding of this event and finding out the root cause (as showed in figure 11). The possible worst consequence is that the charging pump may be damaged if the shaft nut continuously loosed.

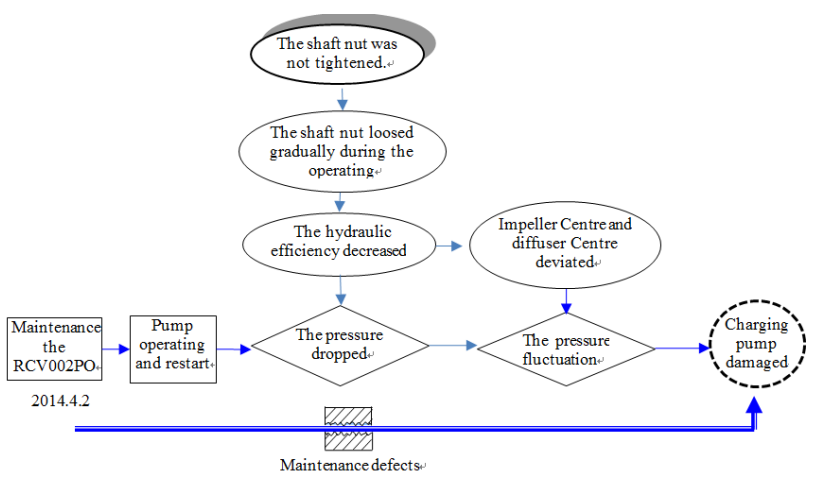

Figure 11. Cause and effect diagram.

\subsection{The root cause}

The root cause of the charging pump's pressure fluctuation is that the shaft nut fails to be tightened. It has been loosing gradually during the operating, resulting in changed position of impeller centre and diffuser centre. 
And the reduced hydraulic efficiency of the pump led to outlet pressure fluctuations.

\subsection{Corrective action}

The shaft nut should be twisted and the glue should be used to prevent the nut from being loosed. Updating the maintenance program to ensure the similar incident will not occur again. Learn the feedback of this event in the whole nuclear power station.

\section{Conclusion}

In this paper, Equipment Failure Root Cause Analysis method is introduced to analysis the charging pump's pressure fluctuation event. The 6-steps sequential process of ERCA are introduced: a) Define the problem of an event, b) Collecting equipment data information, c) Listed the equipment failure modes and analysis their possibility, d) Identify the root cause, e) Formulate the corresponding corrective actions, f) Tracking and assessment the effects of the corrective actions. ERCA' detail analysis process has been showed to find the root cause of this event. And each of 6-steps had been extended analysis.

The root cause of pressure fluctuation of charging pump is the untightened shaft nut, which has been loosing gradually during the operating. The corresponding corrective actions have been formulated. The outlet pressure of the pump has been recovered now.

\section{References}

1. J. Zhu Theory of pump clearance $[\mathrm{J}]$. Journal of Daya bay Nuclear Power, 2002(1);

2. H.Z. He Investigation on screw thread connection loosing problem and the anti-loosing measures [J]. Mechanical development (Chinese), 1993, 3: 43-47.

3. S.Y. Hou Liao R.D. Research status and development trend of screw thread connection loosing process $[\mathrm{J}]$. Structure and Environment Engineering (Chinese), 2014, 41(2): 39-52.

4. H. Tang Loosening and Damage Mechanism of Thread Joined Structures in Nuclear Power Equipment [J]. Nuclear Power Engineering, 1999, 20(2): 111-116.

5. Y. Zhang Zeng G.Y. Zhao D.F. Experimental study on the threaded connection looseness in vibration environment [J]. China Heavy Equipment, 2010 (3): 23-25.

6. KSB, Calculation of axial forces Caused by pump impellers and the suitable axial thrust balancing device, 2014 